\title{
Food firms test fry Pioneer's trans fat-free soybean oil
}

The US Department of Agriculture (USDA) has approved for environmental release one of the first biotech crops aimed at the food industry. The new crop, a genetically modified soybean with an altered fatty acid profile, yields oil that is more stable at high frying temperatures and has a longer shelf life than commodity soybean oil. It was developed by Pioneer Hi-Bred in Johnston, Iowa, a Dupont company. The company received marketing approval for the biotech soybean in June and aims to commercialize it by 2012 . St. Louis-based Monsanto is following close behind, with two soybean products with modified oil profiles in its pipeline.

The new soybean traits may help the biotech industry deliver on a twodecade-long promise: to develop crops with improved nutritional value. Until now, most commercialized biotech crops have been engineered with such traits as pest resistance and herbicide tolerance-traits

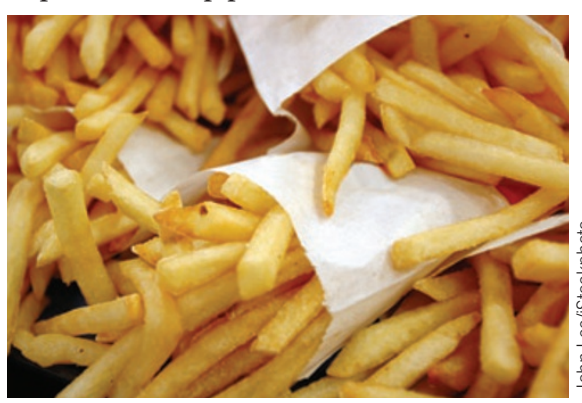

The success of Pioneer's recently approved soy bean, which has been engineered to cut down on trans fats, will depend on how well it is received by the food industry. market has gone from $76 \%$ in 2005 to $64 \%$ today, according to the US Census Bureau. "We hope to recapture that space [for soybeans]," says Pioneer's Russ Sanders, director of enhanced oils.

Pioneer's new soybean oil has an oleic fatty acid content of $>75 \%$, a property that gives it frying and shelf stability comparable to that of palm, high oleic acid canola and hydrogenated soybean oils. It also contains $20 \%$ less saturated fat than commodity soybean oil. Pioneer dubbed the crop "Plenish high-oleic soybeans." Overproduction of oleic acid and decreased levels of linoleic and linolenic acids in Plenish arise from transgenic expression of a fragment of the soybean microsomal omega-6 desaturase gene (FAD2-1) under the control of soybean Kunitz trypsin inhibitor gene promoter, which silences endogenous omega-6 desaturase. The transgenic soybean also carries the $S$-adenosyl-Lmethionine synthat mostly benefit farmers rather than the food industry or consumers. "Heat stability and longer shelf life: these are the things that can light up the food industry, not reduced pesticides," says Tom Hoban, a professor of food science at North Carolina State University in Raleigh.

Pioneer is marketing its new soybean oil as an alternative to partially hydrogenated vegetable oils. For decades, food producers have relied on partially hydrogenated soybean oil because it retains its flavor at high cooking temperatures and for extended periods on the grocery store shelf. But the process of partial hydrogenation produces trans fatty acids, or trans fats, which are known to increase 'bad' low-density lipoprotein (LDL) cholesterol and increase risk of coronary heart disease.

In 2006, the US Food and Drug Administration began requiring food manufacturers to label food with trans fats, and measures to alert the public of the health risks of trans fats ensued. Food producers turned to alternatives, such as palm oil and certain kinds of canola oil, that have more stable frying and shelf life characteristics than those of unhydrogenated soybean oil. As a result, soybean oil's share of the edible fats and oils thetase as a marker to enable initial selection in the laboratory by acetolactate synthase (ALS)-inhibiting herbicide.

The success of the Plenish soybean will depend on how well it is received by the food industry. Pioneer has already set up testing agreements with a dozen undisclosed food companies, says Sanders. The companies will run consumer taste tests, frying tests and shelf life tests-just about anything a food company would normally do with a new ingredient.

Food companies can already choose from an array of oils with modified fatty acid contents developed with conventional breeding. "The hard reality will be how producers of liquid vegetable oils compete," says Terry Etherton, professor of animal nutrition at Penn State in University Park, Pennsylvania.

Food industry representatives say they welcome the new oil option, but see it as a "trial situation," says Jeffrey Barach, vice president of science policy at Grocery Manufacturers Association in Washington, DC ."Each company has to try it out and do some experimental work," he says.

Although Pioneer received the full go-ahead from regulators, the company doesn't plan to

\section{IN brief}

\section{Anti-CD20 patent battle ends}

On June 1, a four-year dispute over a European patent for anti-CD20 drugs to treat rheumatoid arthritis came to an end, with Seattle-based

Trubion winning the dispute. This result frees up the space for anyone with a CD20 program, says Jeff Pepe, associate general counsel at Trubion. Multiple oppositions had been filed against the patent (European Patent 1176981) held jointly by Genentech of S. San Francisco, California, and Biogen Idec of Cambridge, Massachusetts. Trubion was joined by Medlmmune, GenMab, Centocor, the Glaxo Group and Merck Serono, all pursuing anti-CD-20 programs at one time. In 2008, the Opposition Division of the European Patent Office ruled that, as filed, the patent did not meet the necessary requirements, favoring Trubion. Genentech and Biogen appealed in 2009. Finally, at an oral hearing this June, the original ruling was upheld, and no further appeals will be allowed. Ironically, around the time of the hearing, New York-based Pfizer, which acquired Trubion's CD20 programs when it bought Wyeth in 2009, announced they would drop Trubion's lead anti-CD20 compound (TRU015) though retaining the biotech's second generation anti-CD20 monoclonal antibody also in rheumatoid arthritis. For Genentech/Roche "the decision does not impact our expectations with respect to protection against Rituxan [rituximab, anti-CD20 chimeric monoclonal antibody]," says company spokesperson Rubin Snyder.

Laura DeFrancesco

\section{EU states free to ban GM crops}

In July, the European Commission (EC) officially proposed to give member states the freedom to veto cultivation of genetically modified (GM) crops without having to back their decision with scientific evidence on new risks. The reform's goal is to hand back responsibility to individual states and speed up pending authorizations. Anti-GM countries can now choose to opt out whereas biotech-friendly countries can cultivate new GM varieties. However, there is no guarantee it will work. "We are not against freedom for member states, the problem is how the principle is articulated," says Carel du Marchie Sarvaas, director for agricultural biotech at EuropaBio. The proposal stands on two legs: an amendment to directive 2001/18 that must gain the approval of the council of ministers and the European Parliament, and an EC recommendation on coexistence, already effective. The first legalizes national or local bans on growing, the second one achieves the same result by conceding that countries wanting to keep 'contamination' levels well below the labeling threshold can enforce wide isolation distances between GM and conventional or organic fields. "It's a Pandora's box. We are concerned it will create legal uncertainty and unpredictability for farmers and operators," says du Marchie Sarvaas. The reform doesn't target imports of GM material for food or feed, whose approvals are also stalled. Anna Meldolesi 